\title{
EFEITOS DE RAIOS X NA INDUÇÃO DE MUTAÇÕES EM COFFEA ARABICA ${ }^{(1)}$
}

ALCidES CARVALHO. LUIZ CARLOS FAZUOLI e HERCULANo PENNA MEDiNA FILHO, Seçāo de Genética, Instituto Agronómico.

\section{RESUMO}

Sementes autopolinizadas do cultivar Bourbon Vermelho (Coffea arabica L.) gerações $\mathbf{S}_{4}$ e $\mathbf{S}_{\tilde{5}}$ e de linhas puras obtidas a partir de haplóides, foram expostas a irradiaçōes de raios $X$, correspondentes a dosagens de $5.000,10.000,12.500$ e $23.000 \mathrm{R}$. Verificou-se na

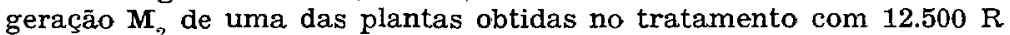
a ocorrência de uma mutação recessiva do tipo angustifólia. Cafeeiros com fenótipo normal, resultantes de sementes irradiadas com 5.000 e $23.000 \mathrm{R}$ foram plantados no campo, em experimentos, cuja produção foi controlada por 14 anos. Notou-se, entre eles, diferenças acentuadas na produção de café cereja. Progênies desses cafeeiros com maior e menor produção, plantadas em outros experimentos e colhidas durante sete anos consecutivos, não revelaram correlação positiva entre a produção das plantas matrizes e suas progênies. O mesmo fato foi observado em um terceiro experimento, cujas produçōes individuais foram seguidas por cinco anos consecutivos. Os dados indicam que não devem ter ocorrido mutações favoráveis que contribuíssem para a melhoria de produção. Como o número de plantas analisadas foi relativamente pequeno, o fato de terem sido observadas mutações sugere a possibilidade de o processo contribuir para acréscimos na variabilidade genética em C. arabica.

\section{INTRODUÇĀO}

O tratamento de sementes por radiações ionizantes vem sendo amplamente empregado em espécies vegetais autógamas para a obtenção de mutações que poderão ser utilizadas em programas de melhoramentc.

(1) Recebido para publicação a 3 de agosto de 1983. 
Os trabalhos, principalmente com cereais, vêm apresentando êxito, quer pelo desenvolvimento de linhagens mais produtivas, com melhores características agronômicas, quer pela resistência a determinados patógenos. Revisões sobre esse assunto são periodicamente realizadas $(\mathbf{9}, \mathbf{1 9}$, 20, 22, 23, 24).

As investigaçōes referentes a Coffea arabica indicam que a variabilidade genética nas populações existentes no Brasil ć reduzida $(\mathbf{3}, \mathbf{4}, \mathbf{1 1})$. Dessa forma, o emprego de mutagênicos seria desejável como uma tentativa de obter mutações que, além de enriquecerem o banco de germoplasma, pudessem também contribuir para acréscimos na produção.

Poucas informaçōes existem sobre os efeitos de agentes mutagênicos na indução de mutações em C. arabica. MOH (15) e MOH \& ORBEGO$\mathrm{ZO}(16)$ indicaram que a resposta do cultivar Arábica dessa espécie a radiações ionizantes é um fenômeno peculiar, pois, irradiando-se as sementes, induz-se, na geração $\mathrm{M}_{\mathrm{k}}$, alta freqüência de variantes morfológicas, particularmente do tipo angustifólia. Essas são de natureza permanente, e as mudanças induzidas geralmente afetam as caracteristicas da planta inteira, formando quimeras apenas em ocasiões muito raras.

CEVALLOS (6) estudou mutantes angustifólia obtidos por radiações gama, na geração $M_{1}$, em seis linhagens de café, dos culłivares Bourbon Vermelho e Arábica de C. arabica. Verificou que a frequiência de plantas do tipo angustifólia foi maior nas linhagens do Arábica do que nas de Bourbon Vermelho e postulou que a indução desse mutante em $\mathbf{M}_{1}$ se relaciona com aberraçōes cromossômicas. A estreita correlação encontrada entre a esterilidade do polem e mutações angustifólia apóia essa teoria.

MONGE (17), analisando a freqüência de grãos moca, uma única semente por fruto em vez de duas, em cafeeiros provenientes de sementes que haviam sido tratadas com nêutrons ou raios $\mathrm{X}$, verificou que a quantidade de sementes moca aumentou proporcionalmente com a dose de radiação usada. A resposta para as plantas irraciiadas com nêutrons foi linear, enquanto para os tratamentos com raios $\mathrm{X}$ foi exponencial. Sugeriu o autor que a elevada freqüência de semertes moca obtida nas plantas irradiadas se deve a aberrações cromossômicas, as quais causam inviabilidade de gametas e, conseqüentemente, uma elevada produção de frutos com apenas uma semente.

CARVALHO (2) e CARVALHO et alii (5), submetendo sementes do cultivar Bourbon Vermelho (C. arabica) à ação de raios $\mathrm{X}$, verificaram que, com dosagens de até $12.500 \mathrm{R}$, algumas sementes germinaram, resultando, porém, em plantas com desenvolvimento mass lento do que as testemunhas não tratadas. No presente trabalho são analisados os efeitos sobre a produção e a ocorrência de mutações em progênies $M_{1}$, $\mathrm{M}_{2}$ e $\mathrm{M}_{3}$ de cafeeiros obtidos nesse tratamento, bem como em progênies de plantas cbtidas em outros tratamentos, com as dosagens de 5.000 , $10.000,12.500$ e $23.000 \mathrm{R}$. 


\section{MATERIAL E METODOS}

As sementes tratadas provieram de flores autofecundadas artificialmente de cafeeiros da geração $S_{4}$ e $S_{5}$ do cultivar Bourbon Vermelho de C. arabica, ou de linhas puras desse cultivar obtidas pela duplicação de cromossomos de formas haplóides. O tratamento das sementes foi realizado no Departamento de Física da Universidade de São Paulo (2). Sémentes secas, sem pergaminho, foram colocadas em caixas de Petri e expostas, no betatron, a radiações de $5.000,10.000,12.500$ e $23.000 \mathrm{R}$ sendo, em seguida, colocadas em outras caixas de Petri, com papel umedecido com água a fim de promover a germinação. As nıudas $\mathrm{M}_{1}$ obtidas foram transplantadas para canteiros protegidos com ripado ou em experimentos no campo, para avaliação da produção. Como controle, foram usadas sementes de 18 cafeeiros correspondentes às gerações $S_{2}$, $S_{3}$ e $S_{6}$ de Bourbon Vermelho, que não sofreram tratamentos com raios $X$. As mudas obtidas foram analisadas em viveiro. Progênies $\mathbf{M}_{2}$ e $\mathbf{M}_{3}$ dos cafeeiros oriundos de sementes tratadas foram analisaqas em viveiro para observação de mutações e, também, em experimentos de campo, no Centro Experimental de Campinas, para observação da produção. Em um dos experimentos ( $\mathrm{EP} 30$ ), foram analisadas progênies $\mathrm{M}_{1}$ de doze cafeeiros originados do tratamento com 5.000, 10.000 e 23.000 R. De um total de 176 plantas, escolheram-se 53 para plantio. Devido ao número variável de plantas por progênie, utilizou-se um delineamento com parcelas inteiramente casualizadas, uma planta por parcela e um cafeeiro por cova. Neste experimento, usou-se como controle : progênie do cafeeiro C357-21 DP-20 derivado de uma planta haplóide de Bourbon Vermelho cujo número de cromossomos fora duplicado. Em outro experimento (EP 52), 15 progênies provenientes de plantas matrizes do EP 30 foram analisadas, em blocos ao acaso, dez repetições, parcelas de uma cova e quatro cafeeiros por cova. De um total de 1.845 plantas, em média 130 por progênie, escolheram-se 40 de cada progênie para plantio. Neste experimento foi usada como testemunha uma progênie de $\mathbf{C}$. arabica cv Mundo Novo (CP 379-19), além de uma de Eourbon Vermelho 1-10-4-4-11-25-2. A produção de café maduro foi seguida no periodo de 1963 a 1969, sendo feitas também observações sobre a altura, diâmetro da copa e aspecto geral das plantas, avaliado subjetivamente, no qual 1 ponto refere-se às piores e 10, às melhores. Avaliaram-se também as plantas quanto ao defeito de frutos sem sementes. No experimento EP 114, foram analisadas 30 progênies derivacias de plantas selecionadas nos ensaios EP 30 e EP 52, em blocos ao acaso, três repetições, parcelas de seis covas e uma planta por cova, num total de 18 plantas por progênie. Para escolha dessas plantas, examinaram-se 3.520 cafeeiros, em média de 130 plantas por progênie. Como testemunha foi usada a progênie Mundo Novo CP379-19, além das progênies de

(2) Os autrires agradecem a colaboração ao Prof. Damy de Souza Santos, que realizou o tratamento. 
Bourbon Vermelho 1-10-4-4-11-29-2, 2-3-9-2 e LC357--21 DP-20. A produção refere-se ao período 1973/78. Algumas progênies aí selecionadas estão ainda em observação em outros experimentos em Campinas.

\section{RESULTADOS}

Os prefixos dos cafeeiros cujas sementes foram tratadas, dosagens empregadas, número de mudas $M_{1}$ obtidas e transplantadas, acham-se no quadro 1.

QUADRO 1. Cafeeiros cujas sementes foram tratadas com raios X em 1952 e 1954 , dosagens utilizadas, número de mudas obtidas e transplantadas, com respectivos prefixos

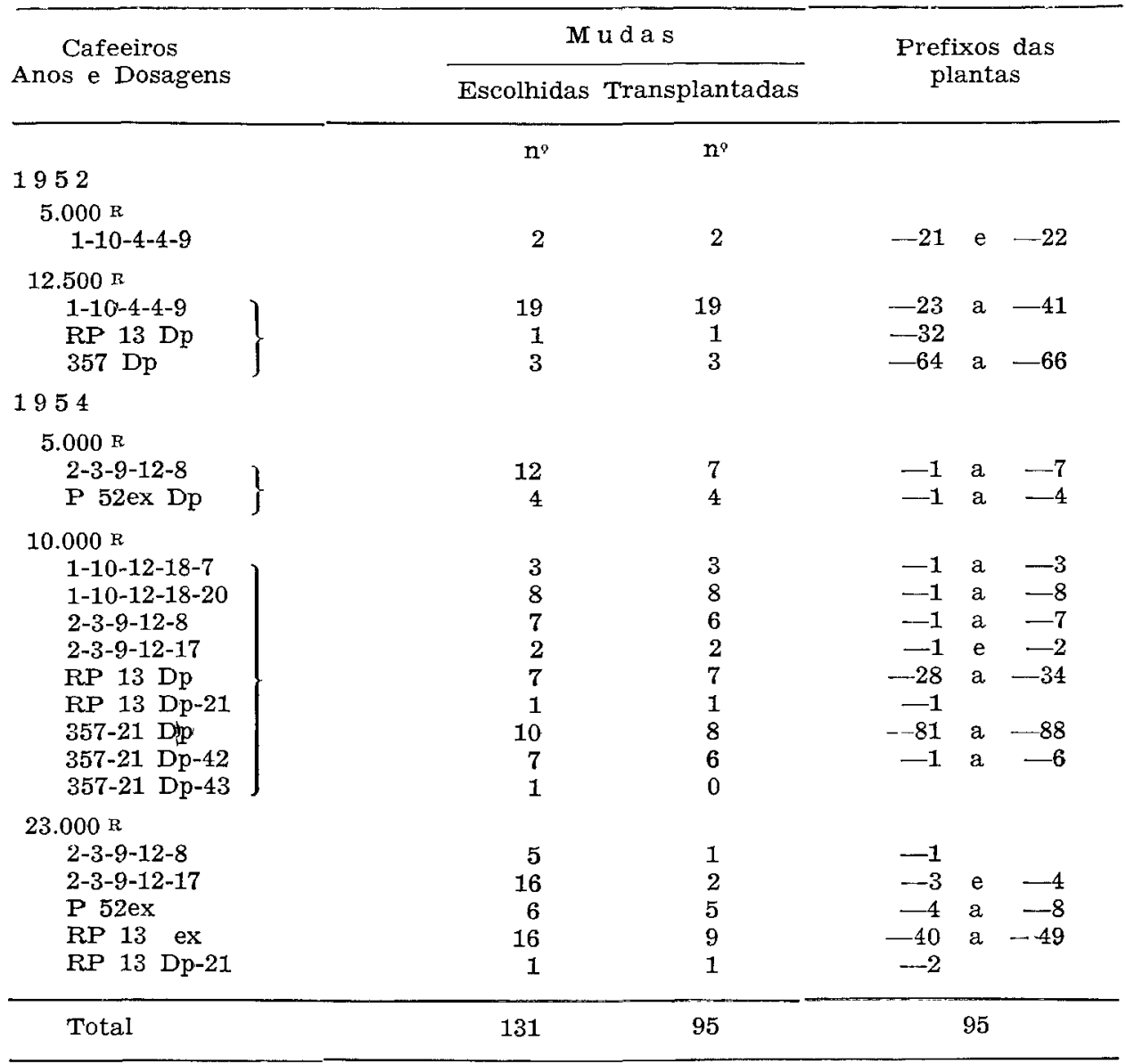

Algumas das mudas $M_{1}$ obtidas (5) foram transplantadas em viveiro para suas respectivas progênies serem estudadas com mais detalhes, além daquelas que foram plantadas no experimento ( $\mathrm{EP} 30$ ), para aná- 
lise da produção. Deve-se reconhecer que o número de cafeeiros plaritados para esse estudo do efeito da radiação sobre a produção de mutações que possam afetar a produtividade foi relativamente pequeno. Isso se deve ao fato de o número de sementes autopolinizadas inicialmente tratadas ter sido pequeno, a germinação precária e o número de mudas aproveitáveis também pequeno. Apesar disso, resolveu-se prosseguir o estudo das gerações subseqüentes a fim de verificar a possibilidade de ocorrência de alguma mutação que viesse beneficiar a produtividade.

\subsection{Análise de gerações $M_{1}, M_{2}$ e $M_{8}$}

Os cafeeiros $\mathrm{M}_{1}$ em viveiro foram autofecundados em várias épocas e, as respectivas progênies $M_{2}$, analisadas. Notou-se que nessa geração, independentemente do tratamento, as plantas em geral apresentaram fenótipo normal. Todavia, foi encontrada uma planta do tipo bulata com 66 cromossomos, além de plantas anormais em algumas progênies, como anã, semelhante a angustifólia (provavelmente aneuplóide) e plantas típicas angustifólia, como indicado nos quadros 2 e 3 (12). Essas variaçōes, em conjunto, foram classificadas como plantas anormais.

QUADRO 2. Progênies de cafeeiros $M_{1}$ que não segregam plantas angustifólia, oriundos de sementes tratadas com raios $X$ e caracteristicas de suas progênies $\mathbf{M}_{2}$

\begin{tabular}{|c|c|c|c|c|c|}
\hline \multirow{2}{*}{$\begin{array}{l}\text { Dosagem } \\
\text { de raios } X\end{array}$} & \multirow{2}{*}{$\begin{array}{l}\text { Progênjes } \\
\text { de cafeeiros } \\
\text { estudados }\end{array}$} & \multirow{2}{*}{$\begin{array}{c}\underset{\text { Plantas }}{\mathbf{M}_{2}} \\
\text { examinadas }\end{array}$} & \multicolumn{3}{|c|}{$\begin{array}{c}\text { Plantas } \mathbf{M}_{2} \text { dos fenótipos } \\
\text { indicados }\end{array}$} \\
\hline & & & Normal & Bulata & Anormais \\
\hline$R$ & $\mathbf{n}^{\circ}$ & $n^{\circ}$ & $\mathrm{n}^{\circ}$ & $\mathrm{n}^{\circ}$ & $\mathrm{n}^{\circ}$ \\
\hline 5.000 & 5 & 791 & 783 & 1 & 7 \\
\hline 10.000 & 18 & 2.052 & 2.041 & - & 11 \\
\hline 12.500 & 17 & 2.735 & 2.673 & 4 & 58 \\
\hline 23.000 & 3 & 405 & 402 & - & 3 \\
\hline
\end{tabular}

QUACiRO 3. Progênies de cafeeiros $\mathrm{M}_{1}$ oriundos de sementes tratadas com raios $\mathrm{X}$ que segregam para plantas angustifolia

\begin{tabular}{|c|c|c|c|}
\hline \multirow{2}{*}{$\begin{array}{c}\text { Dosagens de raios } X(R) \\
\text { e progênies }\end{array}$} & \multicolumn{2}{|c|}{ Plantas dos tipos } & \multirow{2}{*}{$\chi^{2}(3: 1)$} \\
\hline & Normal & Angustifólia & \\
\hline & $\mathrm{n}^{\circ}$ & $n^{\circ}$ & \\
\hline \multicolumn{4}{|l|}{5.000} \\
\hline $2-3-9-13-8-7$ & 48 & 15 & 0,005 \\
\hline \multicolumn{4}{|l|}{10.000} \\
\hline 357-21 Dp 42-6 & 172 & 24 & 16,633 \\
\hline RP 13 Dp 21-1 & 10 & 3 & 0,026 \\
\hline \multicolumn{4}{|l|}{12.500} \\
\hline $1-10-4-4-9-32$ & 143 & 45 & 0,060 \\
\hline $1-10-4-4-9-33$ & 277 & 30 & 37,160 \\
\hline
\end{tabular}


Verificou-se que os cafeeiros de prefixo 1-10-4-4-9-32, 2-3-9-12-8-7 e RP 13 Dp-21-1 são possivelmente heterozigotos para um fator genético angustifólia, segregando na proporção fenotípica de 3:1 ( $\chi^{2}$ ajustado de 0,$06 ; 0,01$ e 0,03 respectivamente). Os cafeeiros 357-21 Dp-42-6 e 1-10-4-4-9-33 segregam anormalmente para essa característica (Quadro 3). Esse último caso poderia ser simplesmente uma segregação anormal de um fator genético ou tratar-se de aneuplóides do tipo monossômico. O fenótipo angustifólia ocorre com freqüência entre os monossômicos. A transmissão dessa aneuploidia para a progênie é, no entanto, irregular e normalmente abaixo do teórico esperado, devido à meror viabilidade de gametas e/ou embriōes aneuplóides (14). Entretanto, as 23 plantas angustifólia $\mathrm{M}^{2}$ derivadas da progênie 1-10-4-4-9-33, por sua vez, deram apenas plantas $\mathrm{M}_{3}$ de fenótipo angustifólia, num total cie 2.231 indivíduos, como mostram os dados do quadro 4. Isso indica que eram homozigotas para fator genético angustifólia, excluindo, portanto, a possibilidade de tratar-se de aneuploidia.

As gerações $M_{3}$ de várias outras dessas plantas $M_{2}$ são também apresentadas no quadro 4 . Verifica-se que 36 plantas fenotipicamente normais deram progênies constituídas apenas de plantas normais, enquanto 13 outras, também de fenótipo normal, revelararn ser heterozigotas e, embora atipicamente, segregam para plantas normais e do tipo angustifólia. Na progênie de um cafeeiro classificado como angustifólia anormal, observaram-se também plantas normais e angustifólia. Três cafeeiros derivados da planta matriz $\mathbf{M}_{2}$ angustifólia 1-10-4-4-9-32 deram apenas plantas angustifólia em suas progênies, como indicado no quadro 4 .

Sementes autofecundadas de 18 cafeeiros correspondentes a gerações $S_{2}$ e $S_{6}$ de Bourbon Vermelho, que não foram tratadas com raios $\mathrm{X}$, deram um total de 1.399 descendentes, todos com folhas do tipo normal, isto é, não segregaram para plantas angustifólia.

\subsection{Cafeeiros em experimentos de produção}

As produções no experimento EP 30, em quilogramas de café cereja, foram anotadas para todas as plantas no período 1958-71. Os dados de produção, bem como a variação constatada, acham-se no quadro 5 . Nota-se que as produções foram reduzidas e bastante variáveis, embora essa variação possa ser em parte devida ao ambiente. As melhores produções médias foram obtidas pelas progênies dos cafeeiros 357-21 Dp 42, 357-21 Dp e P 52 Dp, embora suas médias tenham sido menores do que a da testemunha. Apenas algumas plantas tiveram um desenvolvimento ótimo. A maioria, no entanto, apresentou desenvolvimento de bom a regular.

Os dados de produções médias das progênies do experimento EP 52, em quilogramas de café maduro, bem como os limites da amplitude de 


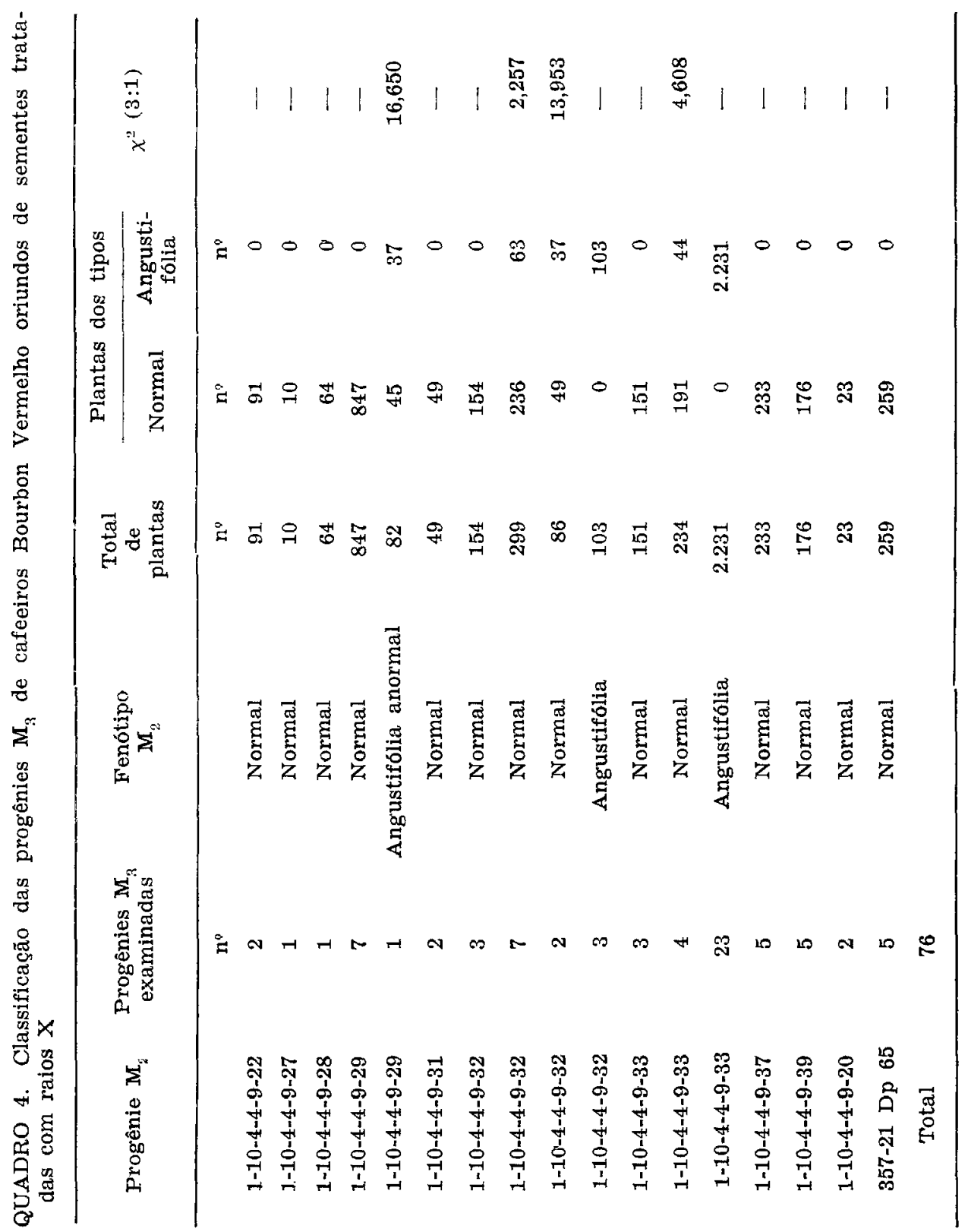




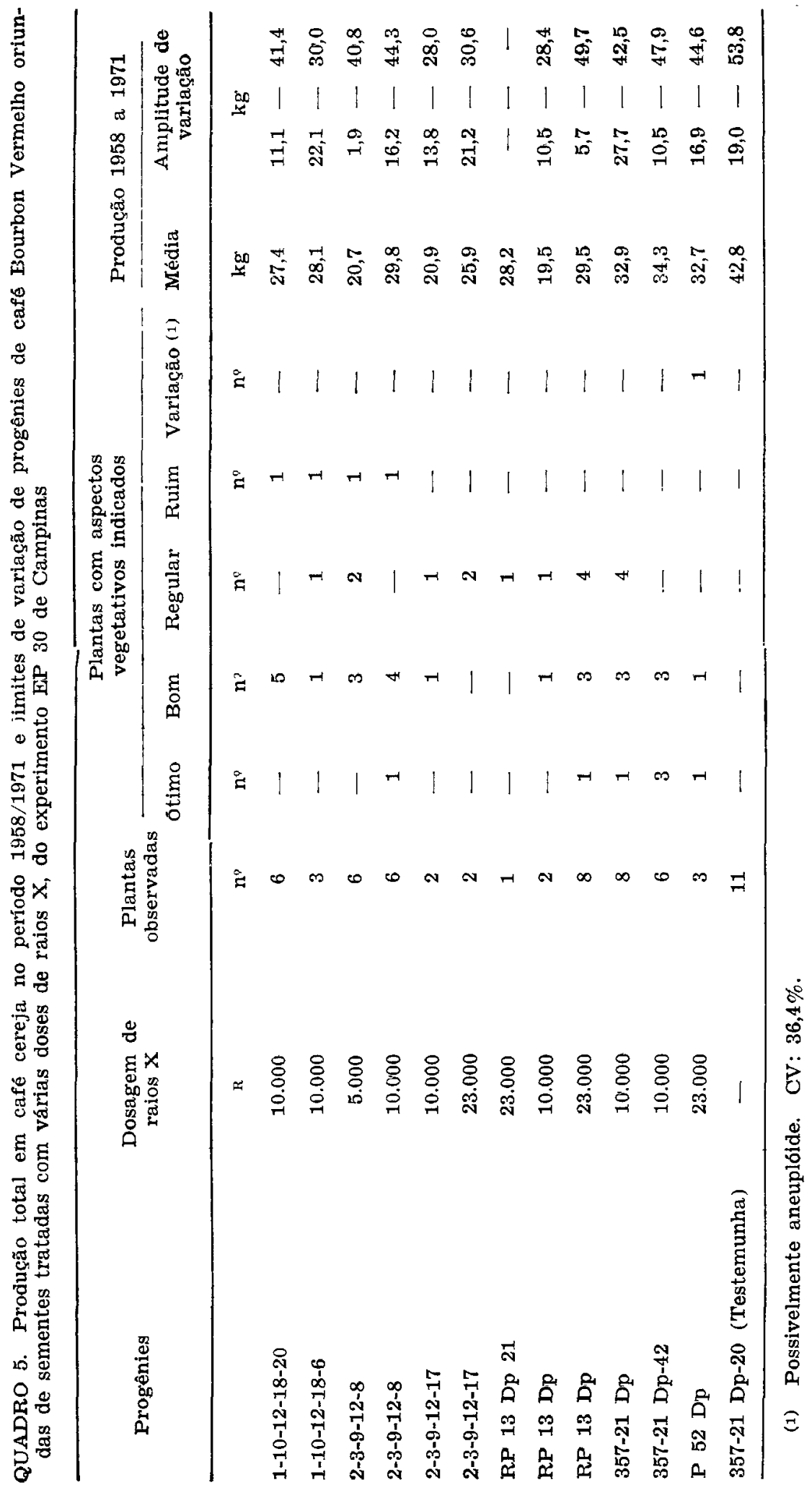


variação, acham-se no quadro 6 . Nota-se que essas progênies $M_{2}$, que são derivadas de plantas $\mathrm{M}_{1}$ selecionadas do experimento EP 30 , são, em geral, pouco produtivas em comparação com as da testemunha Mundo Novo CP 379-19, porém semelhantes à do padrão Bourbon Vermelho, sem tratamento, 1-10-4-4-11-29-2.

QUADRO 6. Produção média por planta, em quilogramas de frutos maduros, de várias progênies $\mathbf{M}_{\text {; }}$ derivadas de plantas matrizes $\mathbf{M}_{1}$ ae Bourbon. Vermelho no periodo 1963/69 e de progênies de Bourbon Vermelho e Mundo Novo do experimento EP 52 de Campinas

\begin{tabular}{|c|c|c|c|c|c|c|c|}
\hline \multirow{3}{*}{$\begin{array}{l}\text { Dosagem de } \\
\text { radiação (R) } \\
\text { e progênies }\end{array}$} & \multirow{3}{*}{$\begin{array}{l}\text { Produçãc } \\
\text { média }\end{array}$} & \multirow{3}{*}{$\begin{array}{c}\text { Amplitude } \\
\text { de } \\
\text { variação }\end{array}$} & \multirow{3}{*}{$\begin{array}{l}\text { Aspecto } \\
\text { vegeta- } \\
\text { tivo (1) }\end{array}$} & \multicolumn{4}{|c|}{ Característica } \\
\hline & & & & \multirow{2}{*}{$\begin{array}{l}\text { Altura } \\
\text { de copa }\end{array}$} & \multirow{2}{*}{$\begin{array}{l}\text { Frutos } \\
\text { chochos }\end{array}$} & \multicolumn{2}{|c|}{ Plantas } \\
\hline & & & & & & a & $\mathbf{b}$ \\
\hline & $\mathrm{kg}$ & kg & & $\mathrm{m}$ & $\%$ & $\mathbf{n}^{0}$ & $\mathrm{n}^{\circ}$ \\
\hline \multicolumn{8}{|l|}{$5.000 \mathrm{R}$} \\
\hline $2-3-9-12-8-5$ & 18,9 & $13,8-23,0$ & 4,2 & 2,37 & 3,8 & 0 & 10 \\
\hline $2-3-9-12-8-7$ & 17,4 & $8,8-25,6$ & 3,8 & 2,30 & 3,5 & 0 & 10 \\
\hline $2-3-9-12-8-6$ & 16,5 & $7,8-22,9$ & 4,3 & 2,40 & 6,9 & 0 & 10 \\
\hline \multicolumn{8}{|l|}{$10.000 \mathrm{R}$} \\
\hline $2-3-9-12-8-13$ & 22,1 & $12,7-30,4$ & 5,2 & 2,52 & 20,4 & 5 & 5 \\
\hline $2-3-9-12-8-12$ & 21,8 & $13,0-27,6$ & 5,6 & 2,50 & 4,4 & 0 & 10 \\
\hline $2-3-9-12-8-14$ & 19,6 & $15,2-26,6$ & 5,0 & 2,41 & 5,2 & 0 & 10 \\
\hline $2-3-9-12-8-10$ & 23,4 & $11,2-27,4$ & 5,0 & 2,44 & 4,2 & 0 & 10 \\
\hline $2-3-9-12-8-11$ & 23,1 & $10,6-30,3$ & 4,8 & $2,5 \overline{5}$ & 3,9 & 0 & 10 \\
\hline $357-21$ Dip-42-5 & 23,3 & $17,0-30,4$ & 4,8 & 2,39 & 2,9 & 0 & 10 \\
\hline $357-21 \quad D p-42-2$ & 21,8 & $11,3-29,3$ & 5,8 & 2,47 & 3,7 & 0 & 10 \\
\hline $357-21$ Dp-42-1 & 20,9 & $15,9-25,8$ & 4,9 & 2,45 & 4,63 & 0 & 10 \\
\hline $357-21$ Dp-42-4 & 19,8 & $9,8-28,6$ & 5,6 & 2,46 & 10,2 & $\mathbf{1}$ & 9 \\
\hline $357-21 \quad D p-42-6$ & 20,5 & $14,4-25,8$ & 4,5 & 2,54 & 6,4 & 0 & 10 \\
\hline $357-21 \quad D p-42-3$ & 21,6 & $14,9-25,9$ & 5,2 & 2,42 & 11,6 & 2 & 8 \\
\hline \multicolumn{8}{|l|}{ Sem tratamento } \\
\hline CP $379-19$ & 35,1 & $27,8-41,8$ & 7,2 & 2,83 & 5,3 & 0 & 10 \\
\hline $1-10-4-4-11-29-2$ & 18,2 & $12,6-21,8$ & 4,1 & 2,36 & 6,5 & 0 & 10 \\
\hline
\end{tabular}

(1) Pontos dados subjetivamente: 1: péssimo aspecto; 10: ótimo; a: com alta quantidade de frutos sem sementes; $b$ : com baixa quantidade de frutos sem sementes. DMS (Tukey $5 \%=6,4 \mathrm{~kg}$ ). $\mathrm{CV}=19,3 \%$.

Quanto ao aspecto vegetativo, avaliado através de pontos dados subjetivamente, verifica-se que as progênies derivadas do cafeeiro 2-3-9-12-8 (5.000 R) apresentam-se de pior aspecto e semelhantes à testemunha 1-10-4-4-11-29-2. A altura média dessas plantas também se revelou igual à da testemunha. No que se refere a lojas do fruto seni sementes, apenas uma planta, 2-3-9-12-8-13 apresentou $20 \%$ de lojas com esse defeito, sendo o mesmo também verificado em cinco plantas de sua progênie. Esse defeito ocorreu em uma planta da progênie 357-21 Dp-42-4 e em duas plantas da progênie 357-21 Dp-42-3. Nas progênies das testemunhas, não foi verificada essa anormalidade. 
Os dados de seis anos de produções consecutivas das progênies $\mathrm{M}_{2}$ derivadas das plantas $M_{1}$ selecionadas no ensaio EP 30 e progênie $M_{3}$ de plantas matrizes $\mathrm{M}_{2}$ do EP 52 e que constituem o ensaio EP 114, acham-se no quadro 7. Nota-se que as progênies $M_{2}$ e $M_{3}$ continuam com produ-

QUADRO 7. Produção média por planta no período 1973-78, em quilogramas de frutos maduros, de progênies $\mathbf{M}_{2}$ e $\mathbf{M}_{3}$ de Bourbon Vermelho do experimento EP' 114, selecionadas nos experimentos EP 30 e EP 52 de Campinas e, também, de outras progênies de Bourbon Vermelho e características vegetativas

\begin{tabular}{|c|c|c|c|c|c|c|}
\hline \multirow{2}{*}{\multicolumn{2}{|c|}{$\begin{array}{l}\text { Dosagem de radiação } \\
\text { (R) e progênies }\end{array}$}} & \multirow{2}{*}{$\begin{array}{l}\text { Produção } \\
\text { média }\end{array}$} & \multirow{2}{*}{$\begin{array}{l}\text { Amplitude de } \\
\text { variação }\end{array}$} & \multirow{2}{*}{$\begin{array}{l}\text { Aspecto } \\
\text { vegetativo }\end{array}$} & \multicolumn{2}{|c|}{ Copa } \\
\hline & & & & & Altura & Diâmetro \\
\hline & & $\mathrm{kg}$ & $\mathrm{kg}$ & pontos & $\mathrm{cm}$ & $\mathrm{cm}$ \\
\hline \multicolumn{7}{|c|}{ EP $30 \quad 5.000^{R}$} \\
\hline \multirow{2}{*}{\multicolumn{2}{|c|}{$\begin{array}{l}2-3-9-12-8-5 \\
2-3-9-12-8-6\end{array}$}} & 14,8 & $10,9-21,4$ & 4,8 & 203 & 191 \\
\hline & & 11,5 & $1,4-21,4$ & 4,2 & 194 & 188 \\
\hline \multicolumn{7}{|c|}{ EP $30 \quad 10.000 \mathrm{R}$} \\
\hline & $357-21$ Dp $42-1$ & 13,1 & $2,3-25,6$ & 3,4 & 186 & 186 \\
\hline & $357-21$ Dp $42-3$ & 13,1 & $6,8-26,5$ & 3,9 & 185 & 179 \\
\hline & $357-21$ Dp $42-2$ & 14,1 & $6,7-25,7$ & 4,0 & 196 & 185 \\
\hline & 357-21 Dp 42-4 & 11,8 & $6,2-20,4$ & 3,6 & 195 & 184 \\
\hline & $357-21$ Dp $42-5$ & 11,8 & $1,4-19,9$ & 3,3 & 196 & 183 \\
\hline & $357-21$ Dp $42-6$ & 16,7 & $5,9-34,2$ & 4,0 & 200 & 190 \\
\hline & $2-3-9-12-8-10$ & 12,9 & $8,2-18,0$ & 4,7 & 199 & 190 \\
\hline & $2-3-9-12-8-13$ & 12,1 & $6,3-22,5$ & 4,7 & 194 & 192 \\
\hline & $2-3-9-12-8-11$ & 14,1 & $2,2-22-8$ & 4,6 & 206 & 187 \\
\hline & $2-3-9-12-8-12$ & 12,5 & $8,7-23,4$ & 4,2 & 199 & 188 \\
\hline & $2-3-9-12-8-14$ & 11,2 & $4,1-21,6$ & 3,9 & 191 & 186 \\
\hline \multicolumn{7}{|c|}{ EP 30 sem tratamento } \\
\hline & LC 357-21 Dp-20 & 14,0 & $2,5-25,7$ & 3,4 & 191 & 190 \\
\hline \multicolumn{7}{|c|}{ EP $52 \quad 5.000 \mathrm{R}$} \\
\hline & $2-3-9-12-8-5$ & 18,5 & $10,7-28,1$ & 5,2 & 211 & 196 \\
\hline & $2-3-9-12-8-6$ & 15,3 & $7,4-29,7$ & 5,1 & 221 & 188 \\
\hline \multicolumn{7}{|c|}{ EP $52 \quad 10.000 \mathrm{R}$} \\
\hline & 357-21 Dp 42-1 & 12,5 & $4,2-18,5$ & 3,6 & 184 & 185 \\
\hline & $357-21$ Dp $42-2$ & 13,7 & $8,1-22,0$ & 3,6 & 194 & 193 \\
\hline & $357-21$ Dp $42-3$ & 14,4 & $4,6-24,9$ & 3,9 & 202 & 188 \\
\hline & $357-21$ Dp $42-4$ & 11,2 & $4,3-17,1$ & 3,0 & 172 & 192 \\
\hline & $357-21$ Dp $42-5$ & 12,8 & $6,3-24,1$ & 3,4 & 197 & 185 \\
\hline & $357-21$ Dp $42-6$ & 16,5 & $4,0-29,2$ & 4,4 & 208 & 199 \\
\hline & $2-3-9-12-8-10$ & 14,5 & $7.0-20,8$ & 5,1 & 208 & 189 \\
\hline & $2-3-9-12-8-11$ & 13,9 & $6,2-18-3$ & 4,3 & 195 & 181 \\
\hline & $2-3-9-12-8-12$ & 11,6 & $7,3-26,2$ & 3,8 & 191 & 183 \\
\hline & $2-3-9-12-8-13$ & 13,1 & $3,8-21,9$ & 4,9 & 216 & 199 \\
\hline & $2-3-9-12-8-14$ & 11,8 & $6,7-17,2$ & 3,8 & 197 & 190 \\
\hline \multicolumn{7}{|c|}{ EP 52 sem tratamento } \\
\hline & $1-10-4-4-11-29-2$ & 13,2 & $4,9-20,3$ & 4,1 & 196 & 187 \\
\hline & CP $379-19$ & 22,7 & $15,4-31,9$ & 6,9 & 245 & 198 \\
\hline \multicolumn{7}{|c|}{ I 20 sem tratamento } \\
\hline-2 & $2-3-9-2$ & 14,5 & $10,3-20,6$ & 4,3 & 196 & 198 \\
\hline
\end{tabular}

DMS (Tukey $5 \%=7,4 \mathrm{~kg}) . \quad \mathrm{CV}=16,7 \%$. 
ções bem reduzidas, não se notando nenhum progresso em relaçāo à testemunha. No tocante ao aspecto vegetativo, os descendentes do cafeeiro 357-21 Dp-42 são menos vigorosos do que o controle Mundo Novo. O mesmo parece ocorrer com relação à altura média e diâmetro da copa nos diversos tratamentos.

No quadro 8 acham-se indicadas as produções de frutos maduros das plantas matrizes $\mathrm{M}_{1}$ (EP 30 ) e a produção média da progênie $\mathbf{M}_{2}$ (EP 52) e produçōes das progênies $M_{2}$ e $M_{3}$ do EP 114 de Campinas. Não se verificou correlação positiva entre as produções das plantas $M_{1}$ comparadas com as das progênies $M_{2}$ e $M_{3}$.

QUADRO 8. Comparação entre as produções em quilogramas de frutos maduros de plantas matrizes $\mathbf{M}_{1}$ do Ensaio de Progênies EP 30 de Campinas e a das progênies $\mathbf{M}_{2}$ do EP 52 e das progênies $\mathbf{M}_{2}$ e $M_{3}$ do experimento EP 114 de Campinas

\begin{tabular}{|c|c|c|c|c|}
\hline \multirow[t]{2}{*}{$\begin{array}{c}\text { Dosagem de radiação }(R) \\
\text { e planta matriz }(1)\end{array}$} & \multirow[t]{2}{*}{$\begin{array}{l}\text { Produção } \\
\text { total }\end{array}$} & \multirow{2}{*}{$\begin{array}{l}\text { Produção total } \\
\text { média } \\
\text { Progênies } \mathbf{M}_{2}\end{array}$} & \multicolumn{2}{|c|}{$\begin{array}{l}\text { Produção total } \\
\text { média (3) } \\
\text { Progênies }\end{array}$} \\
\hline & & & $\mathbf{M}=$ & $\mathbf{M}_{3}$ \\
\hline & $\mathrm{kg}$ & $\mathrm{kg}$ & $\mathrm{kg}$ & $\mathrm{kg}$ \\
\hline $2-3-9-12-8-5$ & 40,8 & 18,9 & 14,8 & 18,5 \\
\hline $2-3-9-12-8-6$ & 20,5 & 16,5 & 11,5 & 15,3 \\
\hline $2-3-9-12-8-7$ & 20,8 & 17,4 & - & 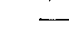 \\
\hline \multicolumn{5}{|l|}{$10.000 \mathrm{R}$} \\
\hline $2-3-9-12-8-10$ & 28,7 & 23,4 & 12,9 & 14,5 \\
\hline $2-3-9-12-8-11$ & 16,2 & 23,1 & 14,1 & 13,9 \\
\hline $2-3-9-12-8-12$ & 30,4 & 21,9 & 12,5 & 11,6 \\
\hline $2-3-9-12-8-13$ & 30,1 & 22,1 & 12,1 & 13,1 \\
\hline $2-3-9-12-8-14$ & 29,1 & 19,6 & 11,2 & 11,8 \\
\hline \multicolumn{5}{|l|}{$10.000 \mathrm{R}$} \\
\hline $357-21 \quad \mathrm{Dp}-42-1$ & 10,5 & 20,8 & 13,1 & 12,5 \\
\hline $357-21 \quad D p-42-2$ & 47,9 & 21,8 & 14,1 & 13,7 \\
\hline $357-21 \quad D p-42-3$ & 31,3 & 21,6 & 13,1 & 14,4 \\
\hline $357-21$ Dp-42-4 & 42,0 & 19,8 & 11,8 & 11,2 \\
\hline $357-21 \quad \mathrm{Dp}-42-5$ & 31,5 & 23,3 & 11,8 & 12,8 \\
\hline $357-21$ Dp-42-6 & 42,7 & 20,5 & 16,7 & 16,5 \\
\hline
\end{tabular}

(1) Plantada no EP 30 - Produção total 1958-71.

(2) Plantada no EP 52 - Produção média 1963-69.

(3) Plantada no EP 114 - Produção total média 1973-78. Progênies $\mathbf{M}_{2}$ derivadas do EP 30 e $\mathbf{M}_{3 ;}$ derivadas do EP 52.

\section{DISCUSSÃO E CONCLUSõES}

Desde os trabalhos pioneiros de MULLER (18) e STADLER (25, 26) sobre o emprego de radiaçōes ionizantes na produção de mutações, e dos trabalhos de GUSTAFSSON (9) sobre a sua utilização na indução de mutações em plantas cultivadas, numerosas são as pesquisas realizadas, as quais vêm indicando o valor desse método na produção de mutações de 
interesse no melhoramento genético das espécies econômicas $(\mathbf{1 9}, \mathbf{2 4}, \mathbf{2 7}$ ) Além de contribuir para ampliar a variabilidade genética, as mutações podem afetar favoravelmente características de interesse econômico (19), embora, em algumas plantas, os resultados não tenham sido significativos (10). Cultivares de amendoim que se destacaram pela maior produtividade foram obtidos $(\mathbf{8}, \mathbf{2 1})$, bem como plantas ornamentais mais atraentes (13). Os extensos trabalhos de GREGORY (8) confirmam a hipótese de que mutações de pequenos efeitos, principalmente sobre a produção, aumentam em freqüência em função exponencial do seu reduzido efeito. Exemplos são dados por esses autores de macromutaçōes obtidas em amendoim e induzidas por radiações.

O tratamento do cafeeiro com radiações ionizantes poderia mostrar-se vantajoso, caso novas mutações pudessem ser utilizadas nas análises genéticas ou no plano geral de melhoramento. O material de Bourbon Vermelho estudado não apresentou variações diferentes ciaquelas já conhecidas (12), possivelmente devido ao fato de poucas plantas terem sido observadas em $\mathrm{M}_{1}$ e nas populações $\mathrm{M}_{2}$. Ocorreram vários tipos de plantas com folhas estreitas, genericamente denominadas de angustifólia e que devem corresponder a aneuplóides, conforme indicado por MENDES (14). Não se verificaram plantas com quimeras, tal como foi observado por MOH \& ORBEGOZO (16). A ausência de quimeras talvez se deva ao pequeno número de células no meristema apical (6) ou ao estado pouco diferenciado do embrião da semente de café, pois, de acordo com DEDECCA (7), o cafeeiro parece normal quanto às camadas histogênicas do caule. Se a haste do cafeeiro se desenvolvesse a partir de uma única célula do corpo, como supõem CARVALHO (2) e $\mathrm{MOH}$ (15), seria mais fácil a produção de mutações. Isso, no entanto, não tem sido observado.

Os dados obtidos mostram que o número de plantas anormais nos cafeeiros resultantes de sementes tratadas aumentou com a dosagem até o limite de $12.500 \mathrm{R}$, diminuindo na dosagem de $23.000 \mathrm{R}$. Algumas das plantas angustifólia obtidas, que parecem constituir mutações diferentes, não são dos tipos aneuplóides, como verificado por MOH \& ORBEGOZO (16), CEVALLOS (6) e MONGE (17). Uma das plantas angustifólia observadas parece não ser aneuplóide, pois as progênies $S_{1}$ e $S_{2}$ são constituídas apenas de plantas angustifólia. Apesar de a ocorrência de um nulissômico ser compatível com esses resultados, neste caso, entretanto, ela parece improvável. A mutação deve ter ocorrido na planta 1-10-4-4-9 (12.500 R). Já se conhecem vários fatores genéticos independentes e que resultam em fenótipos angustifólia, com folhas longas e estreitas e pequena produtividade. Os alelos angustifólia, que ocorrem na condição homozigota nos descendentes dos cafeeiros de prefixos 1-10-4-4-9-32 e 1-10-4-4-9-33, são possivelmente diferentes dos outros fatores angustifólia conhecidos (2), o que está sendo testado através de novas hibridações. O cafeeiro 1-10-4-4-9-29 angustifólia anormal deve constituir um aneuplóide, em vista da segregação anormal que apresenta na descendência formada de plantas normảis e angustifólia. 
Os três experimentos de produção realizados não revelaram, nas diversas geraçōes, nenhum fator afetando favoravelmente a produção, e não se detectou correlação positiva e significativa entre as produções das melhores plantas matrizes $\mathrm{M}_{1}$ e a de suas respectivas progênies.

Segundo SMITH (24), duas são as possibilidades para o melhoramento por meio de indução de mutações: uso das mutações para melhorar caracteres morfológicos e fisiológicos relacionados com ì produção ou ampliação de variabilidade genética para subseqüente realização de seleção. Os dados do presente trabalho mostram que, em relação ao controle, as progênies derivadas de sementes tratadas apresentaram maior variabilidade genética, uma vez que mutações morfológicas conhecidas foram observadas. Provavelmente devido ao reduzido nümero de plantas estudadas no campo, não se verificou a ocorrência de micromutaçōes que afetassem favoravelmente a produção. Em futuros trabalhos visando à utilização de radiações para fins de melhoramento, sugere-se o tratamento e o estudo de grande número de plantas tanto em viveiro como no local definitivo, como mencionado por AASTVEIT (1).

\section{SUMMARY}

\section{EFFECTS OF X-RADIATION ON THE INDUCTION OF MUTATIONS IN COFFEA ARABICA}

Selfed seeds of cv. Bourbon Vermelho (Coffea arabica) from generations $\mathrm{S}_{4}$ and $S_{5}$ and also of pure lines obtained from doubled haploids were exposed to $X$-rays in doses from 5,000 to $23,000 \mathrm{R}$. A recessive mutation of angustifolia type was found in a progeny of generation $\mathbf{M}_{3}$ derived from the treatment with $12,500 \mathrm{R}$. Phenotypically normal plants from seeds irradiated with 5,000 and $23,000 R$ were transplanted to the field and the yields were recorded for fourteen years. Large differences were observed in total yield of individual plants. During seven years, progenies of high and low yielding plants were studied and the data revealed no correlation betwen the yield of the parental plants and their progenies. In another experiment, the yields were followed for five years, and again, no correlation was found. These experiments indicated that no favorable mutation affecting yield occurred. Since the number of plants analysed was relatively small, the fact that some known morphological mutations were observed, suggest that radiation could be used for increasing genetic variability of C. arabica.

\section{REFERENCIAS BIBLIOGRAFICAS}

1. AASTVEIT, K. Plant characters to be improved by mutation breeding. Yielaing ability. In: INTERNATIONAL ATOMIC ENERGY AGENCY. Manual on Mutation Breeding. 2ed. Viena, IAEA, 1977. p.169-170.

2. CARVALHO, A. Advances in coffee production technology: recent advances in our knowledge of coffee trees. Genetics. Coffee \& Tea Industries and the Flavor Field, New York, 81(11):30-36, 1958.

3. —_- Distribuição geográfica e classificação botânica ço gênero Coffea com referência especial à espécie C. arabica. Boletim da Superintendência dos Serviços do Café, São Paulo, 20(226):1138-1145, 1945; 21(227):6-10, (228) :69-73, (229) :127-130, (230) :174-184, 1946. 
4. Carvalho, A. Genética de Coffea. XXIV. Mutantes de Coffea arabica procedentes da Etiópia. Bragantia, Campinas, 18:353-371, 1959.

5. —_ ANTUNES FILHO, H.; NOGUEIRA, R.K. Genética de Coffea. XX. Resultados preliminares do tratamento de sementes de café com raios-X. Bragantia, Campinas, 13:XVII-XX, 1954. (Nota, 7)

6. CEVALLOS, J.V. Estudios sobre el mutante angustifólia de café inducido por radiaciones gamma en la generación $R_{1}$. In: INTERAMERICAN SYMPOSIUM ON THE PEACIFUL APPLICATION OF NUCLEAR ENERGY, 4., Mexico City, 1962. v.2, p.201-209.

7. DEDECCA, D.M. Anatomia e desenvolvimento ontogenético de Coffea arabica L. var. typica Cramer. Bragantia, Campinas, 16:315-366, 1957.

8. GREGORY, W.C. A radiation breeding experiment with peanuts. Radiation Botany, 8:81-147, 1968. (Review paper)

9. GUSTAFSSON, A. Mutations in agricultural plants. Hereditas, 33:1-100, 1947.

10. HARTEN, A.M. van. Mutation breeding techniques and behaviour of irradiated shoot apices of potato. Wageningen, Centre for Agricultural Publishing and Documentation, 1978. 132p. Thesis (Doctoral)

11. KRUG, C.A. Melhoramento do cafeeiro. Doze anos (1933-1944) de pesquisas básicas e aplicadas realizadas na Seção de Genética, Café e Citologia do Instituto Agronômico. Revista da Superintendência dos Serviços do Café, São Paulo, 20(222):863-872, (223) :979-992, (224) :1038-1046, 1945.

12.

\section{nômico, 1937. 17p. (Boletim técnico, 27)}

13. LOOSE, R. Mutation breeding of the hybrids of Rhododendron simsii Planch. (Azalea indica L.). Mutation Breeding Newsletter, 3:15, 1974. (Resumo)

14. MENDES, A.J.T. Observaçōes citológicas em Coffea. XIX. Monossômios. Bragantia, Campinas, 14:137-140, 1955.

15. MOH, C.C. Does a coffee plant develop from one initial cell in the shoot apex of an embryo? Radiation Botany, 1:97-99, 1961.

16. — ORBEGOZO, G. The induction of angustifolia mutants in coffee in the $R_{1}$ generation by ionizing radiations. Genetics, 45:1000, 1960. (Abstract)

17. MONGE, F.S. Frecuencia de café caracolillo en plantas provenientes de semillas irradiadas. Turrialba, $12(4): 209-212,1962$.

18. MULLER, H.J. Artificial transmutation of the gene. Science, 64:84-86, 1927.

19. MUTATION BREEDING NEWSLETTER, Vienna, FAO/IAEA, no 12, 1978.

20. NILAN, R.A.; KLEINHOP, A.; KONZAK, C.F. The role of induced mutation in supplementing natural genetic variability. Annals of the New York Academy of Science, 287:367-384, 1977.

21. PATIL, S.H. Release of X-ray induced groundnut variety TG-1. Mutation Breeding Newsletter, 3:11, 1974. (Resumo)

22. RUTGER, J.N. \& PETERSON, M.L. Improved short stature rice. California Agriculture, 30(6):4-6, 1976. 
23. RUTGER, J.N.; PETERSON, M.L.; HU, C.H.; LEHMAN, W.F. Induction of useful short stature and early maturing mutants in two japonica rice cultivars. Crop Science, 16:631-635, 1976.

24. SMITH, H.H. Radiation in the production of useful mutations. The Botanical Review, 24:1-24, 1958.

25. STADLER, L.J. Chromosome number and the mutation rate in Avena and Triticum. Proceedings of the National Academy of Sciences, 15:876-881, 1929.

26. - - Mutations in barley induced by $\mathrm{X}$-rays and radium. Science, 68:186-187, 1928.

27. VISSER, T.; VERHAEGH, J.J.; DE VRIES, D.P. Pre-selection of compact mutants induced by $\mathrm{X}$-ray treatment in apple and pear. Euphytica, 20:195-207, 1971. 